\title{
Supporting Information for \\ Evaluating Conditions for Strong Coupling between Nanoparticle Plasmons and Organic Dyes using Scattering and Absorption Spectroscopy
}

\author{
Gülis Zengin ${ }^{1}$, Tina Gschneidtner ${ }^{2}$, Ruggero Verre ${ }^{1}$, Lei Shao ${ }^{1}$, Tomasz J. Antosiewicz ${ }^{1,3}$, \\ Kasper Moth-Poulsen ${ }^{2}$, Mikael Käll ${ }^{1}$ and Timur Shegai, ${ }^{1, *}$ \\ ${ }^{1}$ Department of Physics, Chalmers University of Technology, 41296 Göteborg, Sweden \\ ${ }^{2}$ Department of Chemistry and Chemical Engineering, Chalmers University of Technology, 41296 Göteborg, \\ Sweden \\ ${ }^{3}$ Centre of New Technologies, University of Warsaw, Banacha 2c, 02-097 Warsaw, Poland
}

\section{Synthesis of thiolated R6G}

The synthetic procedures of thiolated Rhodamine 6G is described below. All compounds and intermediates are fully characterized, including H-NMR and C-NMR spectra, matrix-assisted laser desorption/ionization (MALDI), high-resolution electrospray ionization mass spectrometry (HR/ESI-Mass), and extinction and fluorescence maxima are given.<smiles></smiles>

Figure S1. The structure of Compound 1

Compound 1: Compound 1 was prepared based on known procedures ${ }^{[1][2]}$. Briefly, to a solution of Rhodamine $6 \mathrm{G}(5 \mathrm{~g}, 10.44 \mathrm{mmol})$ in $\mathrm{EtOH}(80 \mathrm{~mL})$ a solution of $\mathrm{NaOH}(418 \mathrm{mg}$, $10.44 \mathrm{mmol}$ ) in $4 \mathrm{~mL} \mathrm{H}_{2} \mathrm{O}$ was added and the reaction mixture was heated to reflux for $7 \mathrm{~h}$. $200 \mathrm{~mL}$ of cold distilled water was added, and the reaction flask was kept in the fridge for $1 \mathrm{~h}$. The resulting precipitates were filtered off, and dried at $40{ }^{\circ} \mathrm{C}$ in a vacuum oven for $24 \mathrm{~h}$ to give $2 \mathrm{~g}(9.88 \mathrm{mmol} ; 95 \%)$ red colored compound $\mathbf{1}$.

${ }^{1}$ H-NMR-Spectrum (400 MHz, CD $\left.{ }_{3} \mathrm{OD}, 298 \mathrm{~K}\right):\left(\mathrm{Lit}^{[3]}{ }^{[3} \mathrm{CDCl}_{3}\right): \delta_{\mathrm{H}}(\mathrm{ppm}): 8.09(\mathrm{dd}, 1 \mathrm{H}$, $\left.{ }^{3} \mathrm{~J}_{\mathrm{HH}}=7.7,1.5 \mathrm{~Hz}, \mathrm{H}_{\text {arom }}\right), 7.63\left(\mathrm{~m}, 2 \mathrm{H}, \mathrm{H}_{\text {arom. }}\right), 7.22\left(\mathrm{dd}, 1 \mathrm{H},{ }^{3} \mathrm{~J}_{\mathrm{HH}}=7.2,1.5 \mathrm{~Hz}, \mathrm{H}_{\text {arom. }}\right), 7.05$ (s, 2H, $\left.\mathrm{H}_{\text {arom }}\right), 6.86\left(\mathrm{~s}, 2 \mathrm{H}, \mathrm{H}_{\text {arom }}\right), 4.85\left(\mathrm{~s}, 2 \mathrm{H}, \mathrm{H}_{\mathrm{NH}}\right), 3.51\left(\mathrm{~d}, 4 \mathrm{H},{ }^{3} \mathrm{~J}_{\mathrm{HH}}=7.2 \mathrm{~Hz}\right), 2.13(\mathrm{~s}, 6 \mathrm{H})$, $1.35\left(\mathrm{t}, 6 \mathrm{H},{ }^{3} \mathrm{~J}_{\mathrm{HH}}=7.2 \mathrm{~Hz}\right) \cdot{ }^{13} \mathbf{C}-\mathbf{N M R}-$ Spectrum $\left(100 \mathrm{MHz}, \mathrm{CD}_{3} \mathrm{OD}, 298 \mathrm{~K}\right)$ : (Lit. ${ }^{[3]}$ in $\left.\mathrm{CD}_{3} \mathrm{OD}\right): \delta_{\mathrm{C}}(\mathrm{ppm}): 172.2\left(\mathrm{C}_{\text {quart. }}\right.$ /carbonyl $), 161.6\left(\mathrm{C}_{\text {quart }}\right), 157.5,155.9,140.3\left(\mathrm{C}_{\text {quart. }}\right), 132.4$ $\left(\mathrm{C}_{\text {quart. }}\right), 129.6,129.5,129.2,129.0,128.9,124.6,113.7,93.2,37.84\left(\mathrm{CH}_{2}\right), 16.0\left(\mathrm{CH}_{3}\right), 12.6$ $\left(\mathrm{CH}_{3}\right)$; MALDI: $m / z$ : Calc. for $\mathrm{C}_{26} \mathrm{H}_{28} \mathrm{~N}_{2} \mathrm{O}_{3}{ }^{+}: 416.21[\mathrm{M}]^{+}$; found: $416.55[\mathrm{M}]^{+}$, $438.61[\mathrm{M}+\mathrm{Na}]^{+}$; UV/VIS-Spectrum $\left(\mathrm{CH}_{3} \mathrm{OH}\right): \lambda_{\max }(\mathrm{nm}),\left(\log \varepsilon_{\lambda}\left(\mathrm{M}^{-1} \mathrm{~cm}^{-1}\right)\right): 522,(5.2)$; Fluorescence $\left(\mathrm{CH}_{3} \mathrm{OH}\right): \lambda_{\max }(\mathrm{nm}): 547$. 


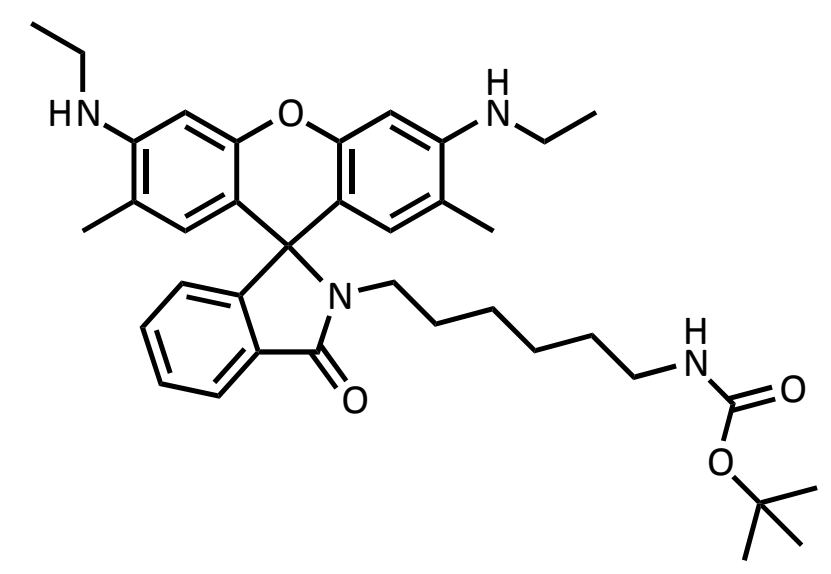

Figure S2. The structure of Compound 2

Compound 2: To the dark purple solution of $1(500 \mathrm{mg}, 1.2 \mathrm{mmol})$ in DMF (16 mL), N,Ndiisopropylethylamine (DIPEA) $(1.6 \mathrm{~mL})$ and $N, N, N^{\prime}, N^{\prime}$-Tetramethyl-O-(1H-benzotriazol-1yl)uronium hexafluorophosphate (HBTU) $(683 \mathrm{mg}, 1.8 \mathrm{mmol})$ were added and stirred at room temperature for $1.5 \mathrm{~h}$. The reaction mixture turned first to slightly pink then to almost colorless $15 \mathrm{~min}$ after the addition of $N$-Boc-1,6-hexanediamine $(388 \mathrm{mg}, 1.8 \mathrm{mmol})$. The solution was stirred for additional $12 \mathrm{~h}$. The crude product was washed with water $(2 \times 50 \mathrm{~mL})$ and brine $(2 \times 30 \mathrm{~mL})$ and extracted with DCM $(3 \times 50 \mathrm{~mL})$. The combined organic phase was dried over $\mathrm{MgSO}_{4}$, filtered off, and dried under reduced pressure. The transparent product was obtained by chromatography (silica, gradient: Hex:EA (30:1), (4:1) (1:1, $\left.\mathrm{R}_{\mathrm{f}}: 0.32\right)$ ) (yield: $715 \mathrm{mg}$, $1.16 \mathrm{mmol}, 97 \%)$.

${ }^{1}$ H-NMR-Spectrum (400 MHz, $\left.\mathrm{CDCl}_{3}, 298 \mathrm{~K}\right): \delta_{\mathrm{H}}(\mathrm{ppm})$ : 8.02-7.77 (m, $1 \mathrm{H}, \mathrm{H}_{\text {arom. }}$ ), 7.587.34 (m, 1H, $\mathrm{H}_{\text {arom. }}$ ), 7.12-6.94 (m, 1H, $\mathrm{H}_{\text {arom. }}$ ), 6.41 (s, 2H, $\left.\mathrm{H}_{\text {arom. }}\right), 6.23$ (s, 2H, $\mathrm{H}_{\text {arom. }}$ ), 4.55 (s, 2H, $\left.\mathrm{H}_{\mathrm{NH}}\right), 3.22(\mathrm{~s}, 4 \mathrm{H}), 3.07(\mathrm{~s}, 2 \mathrm{H}), 2.94(\mathrm{~s}, 2 \mathrm{H}), 1.92(\mathrm{~s}, 6 \mathrm{H}), 1.59(\mathrm{~m}, 2 \mathrm{H}), 1.43(\mathrm{~s}, 6 \mathrm{H}), 1.34$ (s, 4H), 1.24 (m, 5H), 1.03 (s, 4H). ${ }^{13}$ C-NMR-Spectrum (100 MHz, $\left.\mathrm{CDCl}_{3}, 298 \mathrm{~K}\right): \delta_{\mathrm{C}}(\mathrm{ppm})$ : $169.2\left(\mathrm{C}_{\text {quart. /carbonyl }}\right), 153.6\left(\mathrm{C}_{\text {quart./carbonyl }}\right), 151.8,132.4,131.61,129.0,128.1,123.9,122.9$, 65.0 ( $\left.\mathrm{C}_{\text {quart. }}\right), 40.3,29.8,28.6\left(\mathrm{CH}_{3} / \mathrm{C}_{\mathrm{NBOC}}\right), 28.0,26.7,26.3,16.86\left(\mathrm{CH}_{3}\right), 14.4\left(\mathrm{CH}_{3}\right)$; MALDI: $m / z$ : Calc. for $\mathrm{C}_{37} \mathrm{H}_{48} \mathrm{~N}_{4} \mathrm{O}_{4}{ }^{+}$: $612.37[\mathrm{M}]^{+}$; found: $612.0[\mathrm{M}]^{+}, 613.0[\mathrm{M}+\mathrm{H}]^{+}$; UV/VISSpectrum $\left(\mathrm{CH}_{3} \mathrm{OH}\right): \lambda_{\max }(\mathrm{nm}),\left(\log \varepsilon_{\lambda}\left(\mathrm{M}^{-1} \mathrm{~cm}^{-1}\right)\right)$ : 300, (4.27); open form : 530 (4.6); Fluorescence $\left(\mathrm{CH}_{3} \mathrm{OH}\right): \lambda_{\max }(\mathrm{nm})$, open form: 556; HR/ESI-Mass $\mathbf{m} / \mathbf{z} \quad\left(\mathrm{CH}_{3} \mathrm{CN}\right)$ : $\left[\mathrm{C}_{37} \mathrm{H}_{48} \mathrm{~N}_{4} \mathrm{O}_{4}+\mathrm{H}\right]^{+}$: calc.: $613.3748[\mathrm{M}+\mathrm{H}]^{+}$, exper. 613.3754. 


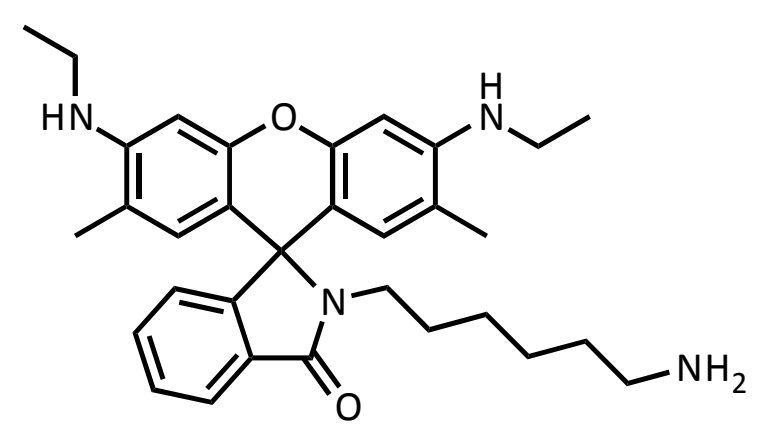

Figure S3. The structure of Compound 3

\section{Compound 3:}

Compound 2 (670 mg, $1.1 \mathrm{mmol})$ was stirred in a mixture of $25 \mathrm{~mL}$ DCM and $6 \mathrm{~mL}$ TFA for $12 \mathrm{~h}$ at room temperature. The solution turns dark purple after 1 minute. The reaction was cooled down to $0{ }^{\circ} \mathrm{C}$ and quenched with the addition of water $(30 \mathrm{~mL})$ and $\mathrm{NaHCO}_{3}$ (until a basic $\mathrm{pH}$ was achieved and the solution turned colorless). The product was extracted with DCM $(3 \times 50 \mathrm{~mL})$, dried over $\mathrm{MgSO}_{4}$, filtered off, and dried under reduced pressure. Colorless compound 2 (541 mg, $1.05 \mathrm{mmol}$, yield: 96\%) was obtained after chromatography (silica, $\left.\mathrm{DCM} / 1 \% \mathrm{MeOH}, 1 \% \mathrm{NEt}_{3}, \mathrm{R}_{\mathrm{f}}: 0.25\right)$.

${ }^{1}$ H-NMR-Spectrum (400 MHz, $\left.\mathrm{CDCl}_{3}, 298 \mathrm{~K}\right):\left(\right.$ Lit. $^{[4]}$ in DMSO) $\delta_{\mathrm{H}}(\mathrm{ppm}): 7.90(\mathrm{~m}, 1 \mathrm{H}$, $\mathrm{H}_{\text {arom. }}$ ), 7.41 (m, 2H, $\left.\mathrm{H}_{\text {arom. }}\right), 7.01\left(\mathrm{~m}, 1 \mathrm{H}, \mathrm{H}_{\text {arom }}\right), 6.34$ (s, 2H, $\left.\mathrm{H}_{\text {arom. }}\right), 6.21$ (s, 2H, $\mathrm{H}_{\text {arom. }}$ ), 5.22 $\left(\mathrm{s}, 2 \mathrm{H}, \mathrm{H}_{\mathrm{NH} 2}\right), 3.47(\mathrm{~m}, 2 \mathrm{H}), 3.20(\mathrm{~m}, 2 \mathrm{H}), 3.07(\mathrm{~m}, 2 \mathrm{H}), 2.66\left(\mathrm{t}, 3 \mathrm{H},{ }^{3} \mathrm{~J}_{\mathrm{HH}}=7.1 \mathrm{~Hz}\right), 2.57(\mathrm{~m}$, 1H), $1.88(\mathrm{~s}, 6 \mathrm{H}), 1.31(\mathrm{~m}, 6 \mathrm{H}), 1.24(\mathrm{~m}, 1 \mathrm{H}), 1.09\left(\mathrm{~s}, 5 \mathrm{H},{ }^{3} \mathrm{~J}_{\mathrm{HH}}=7.1 \mathrm{~Hz}\right) .{ }^{\mathbf{1 3}} \mathbf{C}-\mathbf{N M R}-$ Spectrum $\left(100 \mathrm{MHz}, \mathrm{CDCl}_{3}, 298 \mathrm{~K}\right)$ : (Lit. ${ }^{[4]}$ in $\left.\mathrm{DMSO}\right): \delta_{\mathrm{C}}(\mathrm{ppm}): 168.6\left(\mathrm{C}_{\text {quart. /carbonyl }}\right), 154.1\left(\mathrm{C}_{\text {quart. }}\right)$, $152.1,147.8,131.8,129.1,127.9,124.1,123.1,118.2,106.8,97.0,65.5$ ( $\left.\mathrm{C}_{\text {quart. }}\right), 42.1,40.6$, 38.8, 28.4, 27.1, 26.4, $17.1\left(\mathrm{CH}_{3}\right), 15.2\left(\mathrm{CH}_{3}\right)$; MALDI: $m / z$ : Calc. for $\mathrm{C}_{32} \mathrm{H}_{40} \mathrm{~N}_{4} \mathrm{O}_{2}{ }^{+}: 512.32$ $[\mathrm{M}]^{+}$; found: $513.1[\mathrm{M}+\mathrm{H}]^{+}$; UV/VIS-Spectrum $\left(\mathrm{CH}_{3} \mathrm{OH}\right): \lambda_{\max }(\mathrm{nm}),\left(\log \varepsilon_{\lambda}\left(\mathrm{M}^{-1} \mathrm{~cm}^{-1}\right)\right): 302$, (4.23); open form: 531 (4.7); Fluorescence $\left(\mathrm{CH}_{3} \mathrm{OH}\right): \lambda_{\max }(\mathrm{nm})$, open form: 557. 


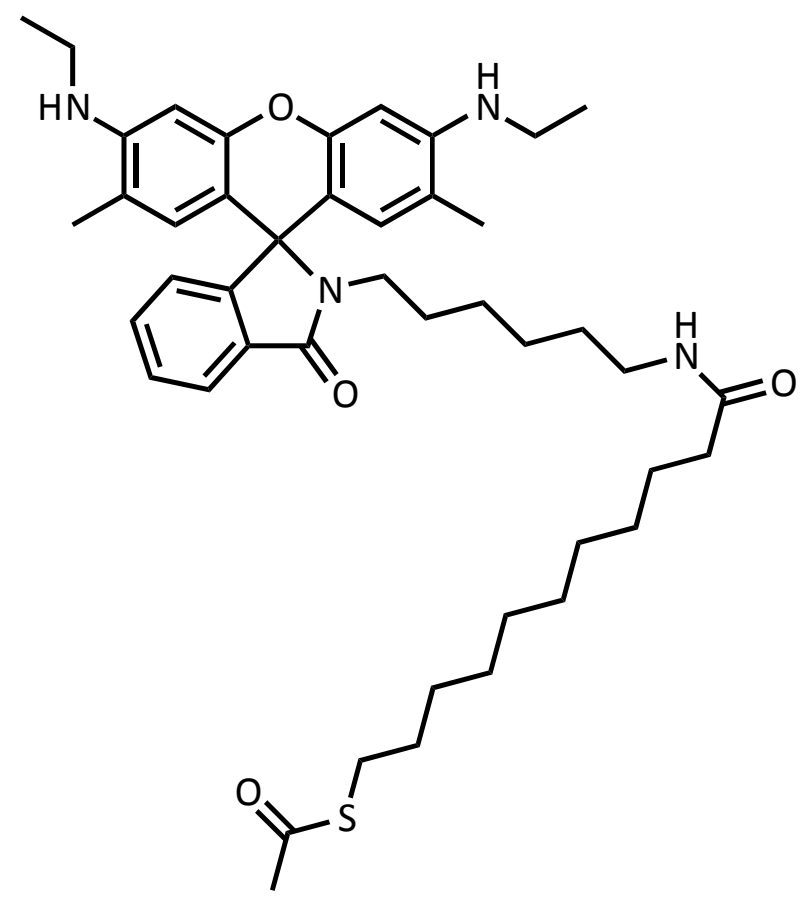

Figure S4. The structure of Compound 4

\section{Compound 4:}

To a solution of 11-(acetylthio)undecanoic acid $(147 \mathrm{mg}, 287 \mu \mathrm{mol})$ in DCM (10 mL), 4dimethylaminopyridine (DMAP) $(3.5 \mathrm{mg}, 28.7 \mu \mathrm{mol})$ and 3-(ethylimino-methyleneamino)$\mathrm{N}, \mathrm{N}$-dimethylpropan-1-amine (EDC) $(55 \mathrm{mg}, 287 \mu \mathrm{mol})$ was added at room temperature and stirred for $4 \mathrm{~h}$. The reaction mixture was cooled to $0{ }^{\circ} \mathrm{C}$ and compound $\mathbf{3}$ was added drop wise. The reaction mixture was allowed to warm up to room temperature and stirred for $16 \mathrm{~h}$. The reaction mixture was washed with water and brine $(2 \mathrm{x}$ each $25 \mathrm{~mL})$ and the product extracted with DCM (3x30 mL). Compound $4(210 \mathrm{mg}, 278 \mu \mathrm{mol}$, yield: 97\%) was obtained after chromatography (silica, gradient DCM, DCM/EA (4:1), DCM + 10\% MeOH, $10 \%$ THF.

${ }^{1}$ H-NMR-Spectrum $\left(400 \mathrm{MHz}, \mathrm{CDCl}_{3}, 298 \mathrm{~K}\right):\left(\delta_{\mathrm{H}}(\mathrm{ppm}): 7.89\left(\mathrm{~m}, 1 \mathrm{H}, \mathrm{H}_{\text {arom. }}\right), 7.41(\mathrm{td}, 2 \mathrm{H}\right.$, $\left.{ }^{3} \mathrm{~J}_{\mathrm{HH}}=7.7,6.7,3.9 \mathrm{~Hz}, \mathrm{H}_{\text {arom. }}\right), 7.01\left(\mathrm{~m}, 1 \mathrm{H}, \mathrm{H}_{\text {arom. }}\right), 6.33$ (s, $\left.2 \mathrm{H}, \mathrm{H}_{\text {arom. }}\right), 6.19$ (s, 2H, $\mathrm{H}_{\text {arom. }}$ ), $5.88\left(\mathrm{~s}, 2 \mathrm{H}, \mathrm{H}_{\mathrm{NH}}\right), 3.72(\mathrm{~m}, 1 \mathrm{H}), 3.19(\mathrm{~m}, 4 \mathrm{H}), 3.08(\mathrm{~m}, 4 \mathrm{H}), 2.83(\mathrm{~m}, 4 \mathrm{H}), 2.30(\mathrm{~m}, 7 \mathrm{H}), 2.15$ $\left(\mathrm{t}, 2 \mathrm{H},{ }^{3} \mathrm{~J}_{\mathrm{HH}}=7.6 \mathrm{~Hz}\right), 1.88(\mathrm{~s}, 6 \mathrm{H}), 1.41(\mathrm{~s}, 1 \mathrm{H}), 1.28(\mathrm{~m}, 16 \mathrm{H}), 1.05(\mathrm{~m}, 6 \mathrm{H}) .{ }^{13} \mathrm{C}-\mathbf{N M R}-$ Spectrum (100 MHz, $\left.\mathrm{CDCl}_{3}, 298 \mathrm{~K}\right): \delta_{\mathrm{C}}(\mathrm{ppm}): 195.8\left(\mathrm{C}_{\mathrm{SCO}}\right), 177.4\left(\mathrm{C}_{\text {quart. } / \text { carbonyl }}\right), 173.09$ $\left(\mathrm{C}_{\text {quart./ carbonyl }}\right), 168.04,153.4,151.4,147.1,132.1,131.0,128.4,127.7,125.2,123.5,122.43$, 117.6, 106.0, 96.3, 67.7 ( $\mathrm{C}_{\text {quart. }}$ ), 39.6, 38.9, 38.2, 36.57, 33.83, 30.37, 29.1, 29.1, 29.1, 29.1, 29.0, 28.9, 28.8, 28.7, 28.5, 27.5, 26.0, 25.6, 25.6, 25.4, 24.6, $16.4\left(\mathrm{CH}_{3}\right), 14.4\left(\mathrm{CH}_{3}\right)$; MALDI: $m / z$ : Calc. for $\mathrm{C}_{45} \mathrm{H}_{62} \mathrm{~N}_{4} \mathrm{O}_{4} \mathrm{~S}^{+}$: $754.45[\mathrm{M}]^{+}$; found: $754.3[\mathrm{M}]^{+}$; UV/VIS-Spectrum $\left(\mathrm{CH}_{3} \mathrm{OH}\right)$ : $\lambda_{\max }(\mathrm{nm}),\left(\log \varepsilon_{\lambda}\left(\mathrm{M}^{-1} \mathrm{~cm}^{-1}\right)\right): 303,(4.22)$; open form: $530(4.6)$; Fluorescence $\left(\mathrm{CH}_{3} \mathrm{OH}\right): \lambda_{\max }$ $(\mathrm{nm})$, open form: 556; HR/ESI-Mass $\mathbf{m} / \mathbf{z}\left(\mathrm{CH}_{3} \mathrm{CN}\right):\left[\mathrm{C}_{45} \mathrm{H}_{62} \mathrm{~N}_{4} \mathrm{O}_{4} \mathrm{~S}+\mathrm{H}\right]^{+}$: calc.: 755.4565 $[\mathrm{M}+\mathrm{H}]^{+}$, exper. 755.4570 . 
<smiles>CC(=O)SCCCCCCCCCCC(=O)O</smiles>

Figure S5. The structure of 11-(acetylthio)undecanoic acid

11-(acetylthio)undecanoic acid was prepared according to a known procedure ${ }^{[5]}$ Briefly, Bromoundecanoic acid ( $2 \mathrm{~g}, 7.54 \mathrm{mmol})$ and potassium thioacetat $(947 \mathrm{mg}, 8.3 \mathrm{mmol})$ were dissolved in $\mathrm{CH}_{3} \mathrm{CN}(20 \mathrm{~mL})$ and stirred for $18 \mathrm{~h}$ at $85{ }^{\circ} \mathrm{C}$. The solvent was removed by reduced pressure and the organic phase was washed with water $(2 \mathrm{x} 75 \mathrm{~mL})$, and extracted with $\mathrm{Et}_{2} \mathrm{O}(3 \mathrm{x} 150 \mathrm{~mL})$. The crude was purified by chromatography (silica, gradient Hex:EA (4:1), $\left.(1: 1), \mathrm{R}_{\mathrm{f}}=0.25\right)$, and the colorless product $(1.87 \mathrm{~g}, 7.16 \mathrm{mmol}$, yield:95\%) was collected.

\section{Obtaining thiolated R6G in fluorescent (open) form}

The compound 4 is a nonfluorescent molecule and the final step is to switch the molecule to fluorescent open form by decreasing $\mathrm{pH}$. The final step is shown in Figure S6.

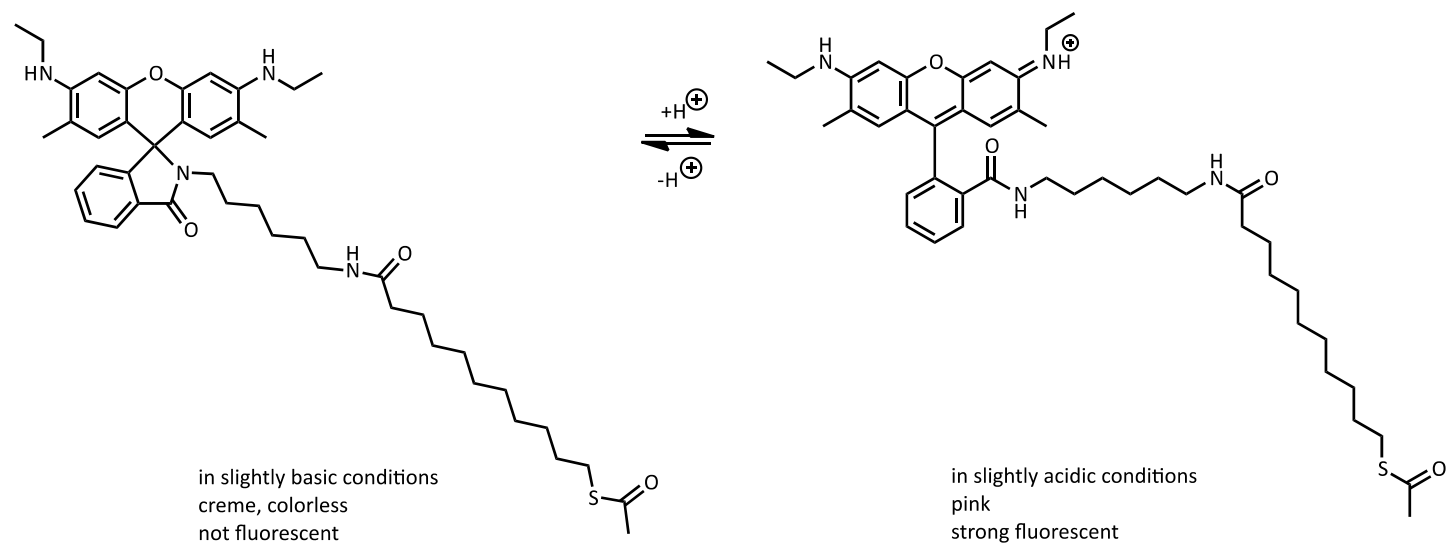

Figure S6. The switch between the fluorescent opened form and the non-fluorescent closed form of thiolated Rhodamine $6 \mathrm{G}$. 


\section{Absorption and fluorescence spectra of thiolated R6G}

The absorption and fluorescence spectra of the fluorescent (open) and non-fluorescent (closed) form of thiolated R6G is given in Figure S7. While there is no absorption and fluorescent emission in the closed form, the molecule switches to open form with addition of $\mathrm{HCl}$ acid.

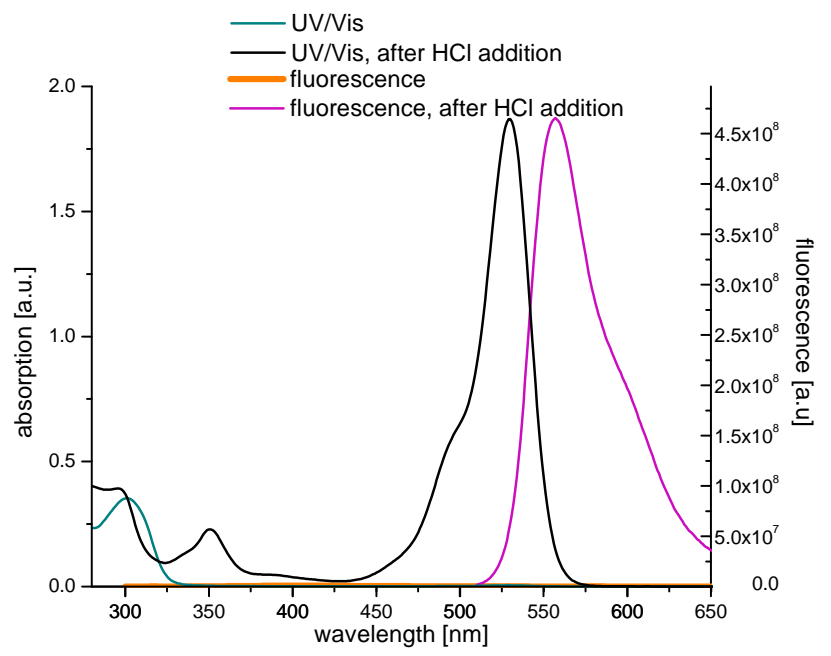

Figure S7. Absorption and fluorescence spectra of open and closed from of thiolated Rhodamine 6G (compound 4).

\section{Comparison of thiolated and ordinary R6G}
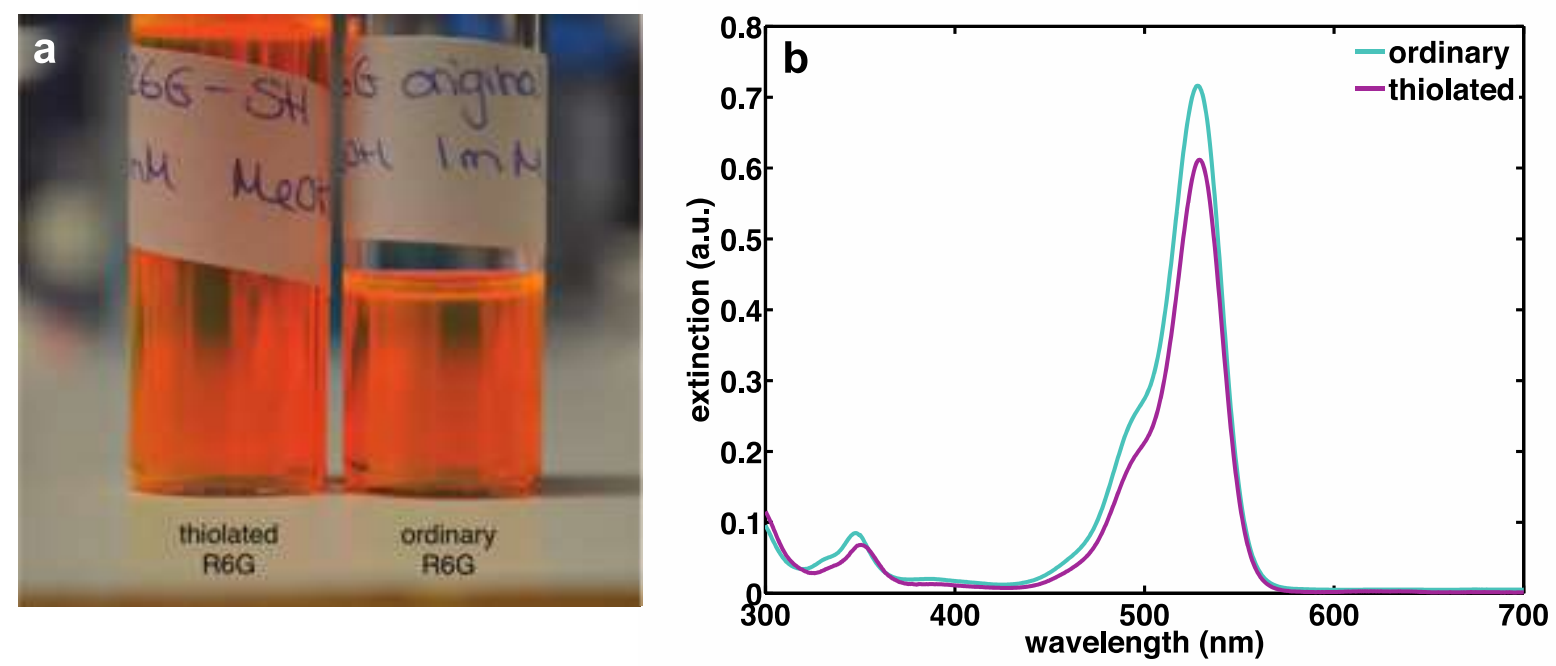

Figure S8. (a) Photograph of $1 \mathrm{mM}$ thiolated (left) and ordinary (right) R6G in methanol. (b) Absorption spectra of thiolated and ordinary R6G in methanol with $10 \mu \mathrm{M}$ concentration. 


\section{The thiol exchange experiment}

The thiol exchange experiment was done in order to quantify the number of R6G molecules absorbed on Ag nanoparticles for both thiolated and ordinary R6G in both methanol and water. Figure S9 shows the schematic diagram of the thiol exchange experiment. Ag nanoparticles prepared by hole-mask colloidal lithography were coated by R6G as described in the methods section. Then each sample was dipped in $20 \mathrm{mM}$ of 1-dodecanethiol in dimethlyformamide (DMF). The idea behind thiol exchange experiment is that 1-dodecamethiol is small thiol molecule and when the dye coated Ag nanoparticle surface left in it with high concentration and long enough waiting time, eventually all the dye molecules are replaced by the 1dodecanethiol. The replaced R6G molecule is going to be released in the solution. By measuring the absorption of the R6G molecule in the same solvent and comparing the absorption value with calibration curve which is done with known concentration of the same dye in the same solvent, the number of R6G are calculated. Calibration curves for both thiolated and ordinary R6G in DMF are given in Figure S10.

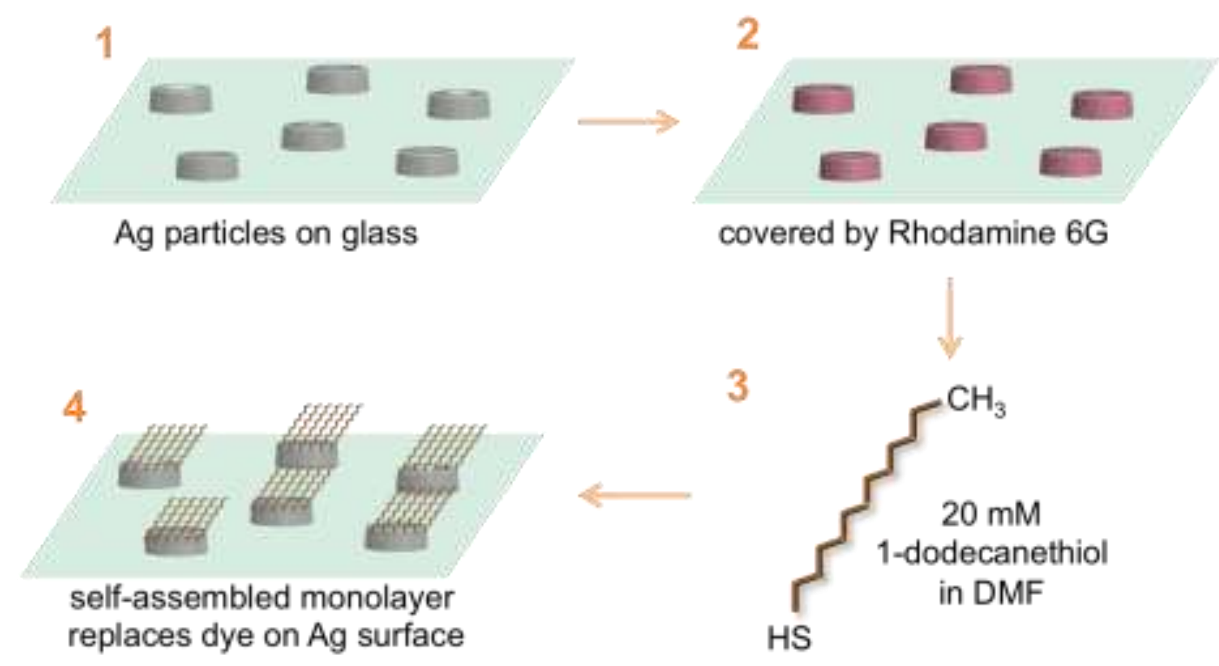

Figure S9 - Schematic diagram describing steps of the thiol exchange experiment in order to quantify the number of R6G molecules bound to Ag surface.
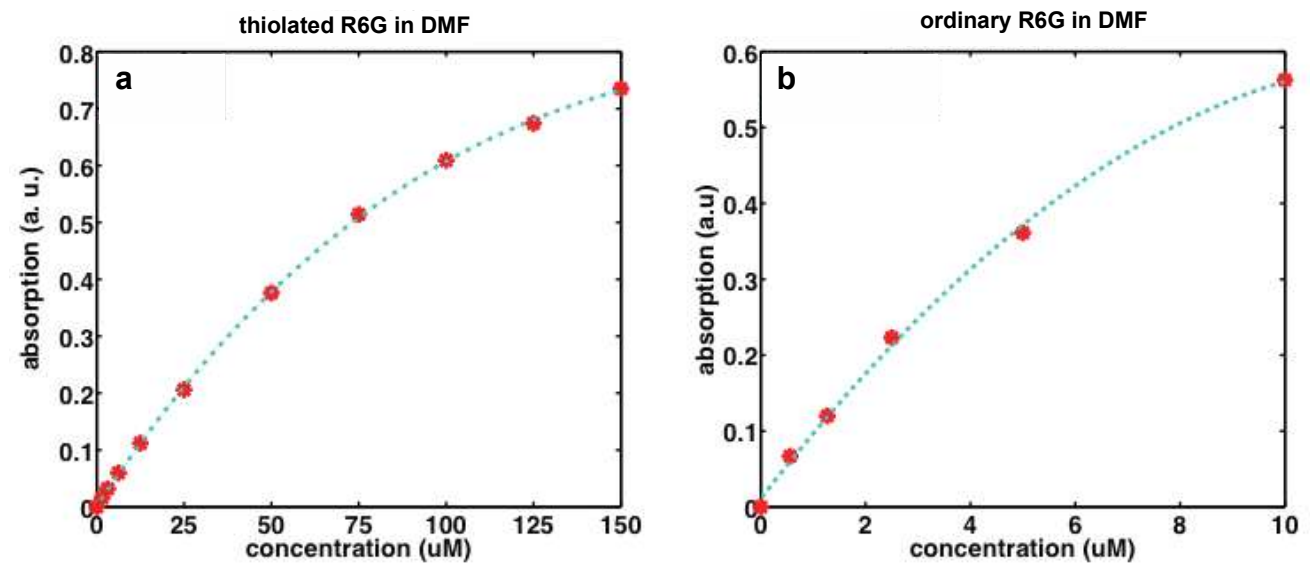

Figure S10. Calibration curves (absorption vs concentration) used for quantification of number of R6G molecules on Ag nanodisks. (a) thiolated R6G (b) ordinary R6G. Both dye solutions are measured in DMF which is the solvent used for thiol exchange experiment. 


\section{Optical characterization of bare Ag particles and samples 1, 2, 3, and 4}
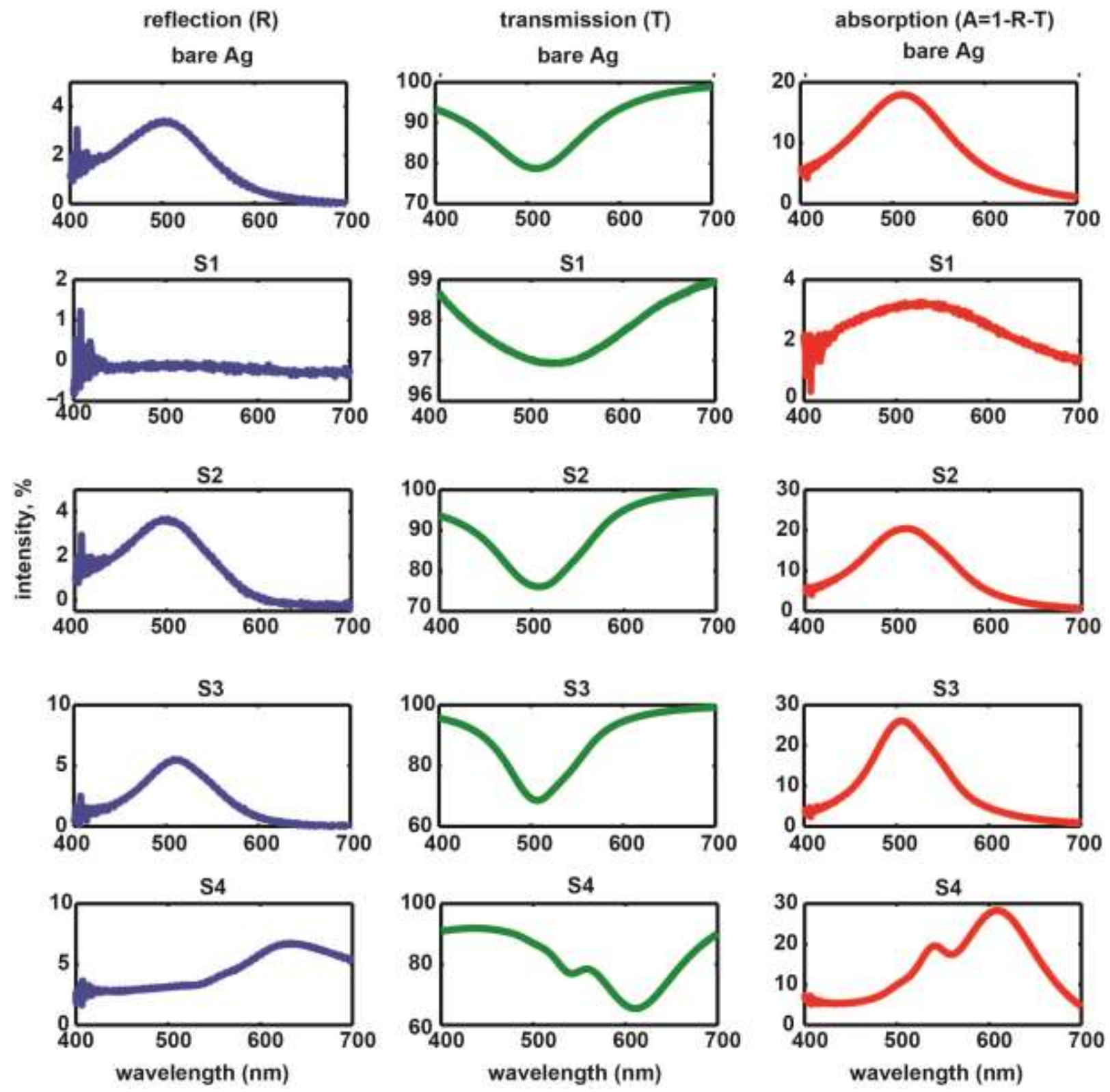

Figure S11 - Reflection, transmission and absorption spectra of the sample 1, sample 2, sample 3 and sample 4. The reflection and transmission measurements were done in Cary 5000 UV-VIS spectrophotometer. Absorption spectra were calculated from the experimental reflection and transmission data with the following formula: A=1R-T. 


\section{Optical characterization of samples 1, 2,3, and 4 on coverglass without Ag particles}
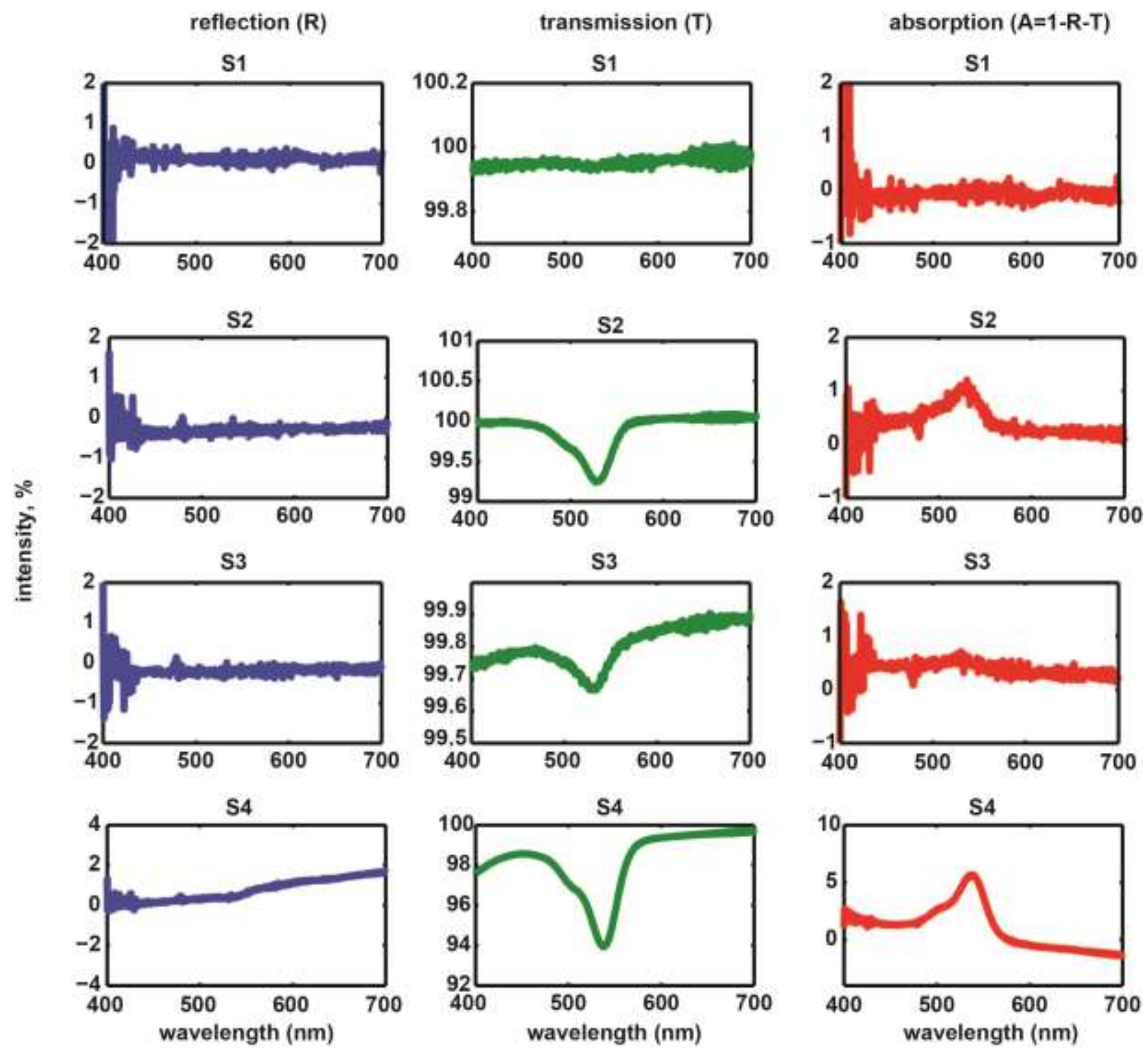

Figure S12 - Reflection, transmission and absorption spectra of the sample 1, sample 2, sample 3 and sample 4 on glass surface without Ag particles in the same conditions. The reflection and transmission measurements were done in Cary 5000 UV-VIS spectrophotometer. Absorption spectra were calculated from the experimental reflection and transmission data with the following formula: A=1-R-T. 


\section{AFM measurements}

Atomic force microcopy images and line profiles of the sample 2 and sample 3 are given in Figure S13. The bare particles sample and Sample 1 have been also measured (see Figure $1 \mathrm{~b}$ in the main manuscript for the bare particle case). Sample 1 and Sample 3 show essentially the same morphology as the bare case. However, for sample 3, while scanning the surface, jumps occur when the tip hits Ag particles. This can be attributed to changes in the adhesion between tip and surface due to the formation of a SAM covering the nanoparticles. These jumps appear even more evident in phase contrast images, which are not shown here. Sample 2 shows similar nanoparticles morphology, but with a slightly larger nanoparticle height. Also, it was possible to observe some R6G aggregates that cover particles and the glass substrate. As a typical example, one of those aggregates can be observed in the bottom right of Figure S13a. For sample 4, as R6G covers the surface with a soft homogeneous material layer, it was not possible to obtain topological contrast even when cantilevers with low spring constant $(5 \mathrm{~N} / \mathrm{m})$ were used for imaging.
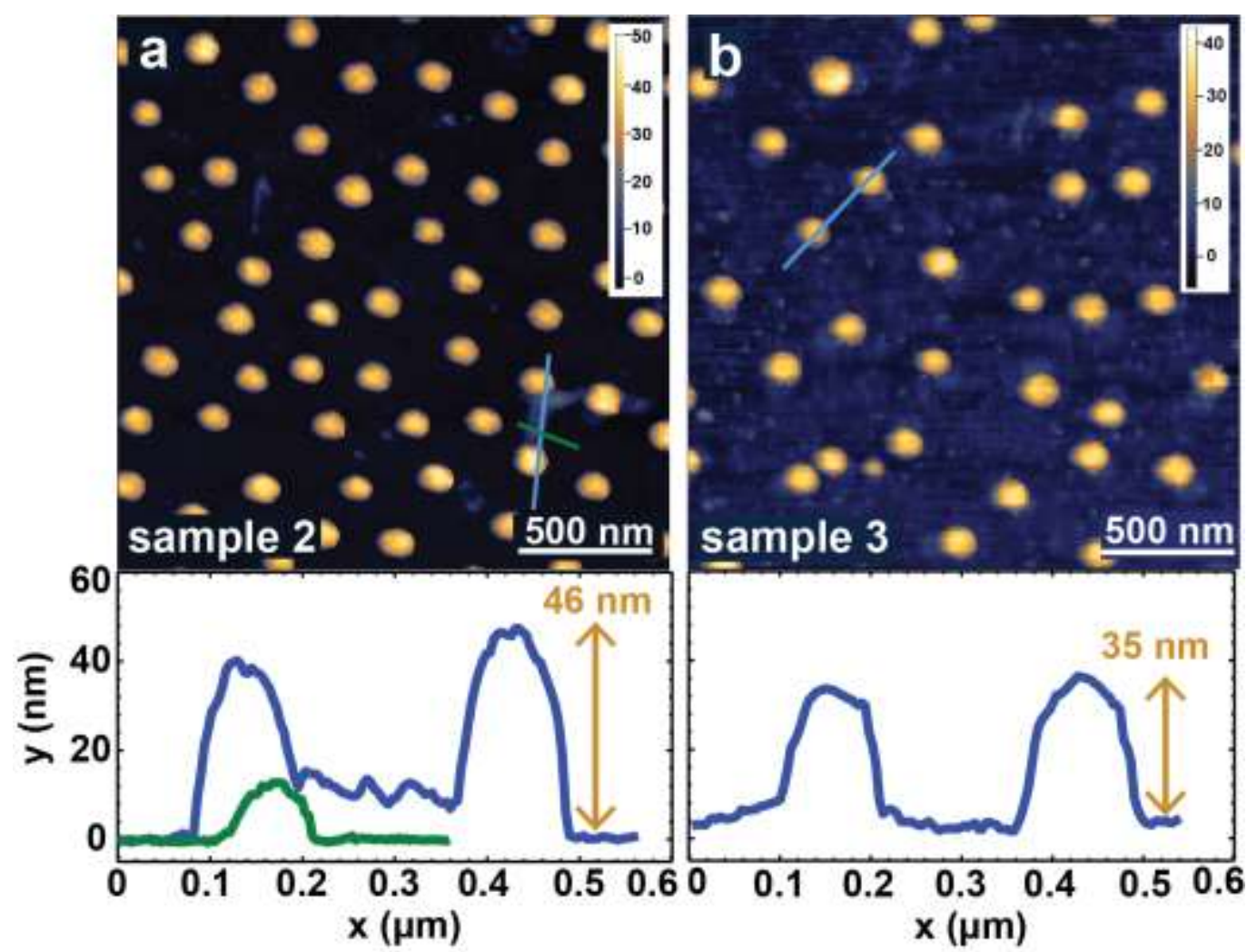

Figure S13 - Atomic force microscopy images showing the distribution and thickness of R6G layer on Ag nanodisks for (a) sample 2 (ordinary R6G in 4:1 water:methanol) and (b) sample 3 (thiolated R6G in methanol). 


\section{Optical characterization of ordinary R6G in high concentrations}

In order to check if it is possible to obtain strong coupling by increasing number of molecules, we spin coated R6G doped PMMA on Ag nanodisks similar to the previously reported studies. ${ }^{[6,7]}$ Ordinary R6G was primarily solved in methanol because of its higher solubility compared to ethanol which was used literature ${ }^{[6]}$. The solubility of ordinary R6G is $835 \mathrm{mM}$ in methanol and $167 \mathrm{mM}$ in ethanol. Then R6G in methanol was mixed with PMMA A2 to obtain $400 \mathrm{mM}$, $200 \mathrm{mM}, 100 \mathrm{mM}, 50 \mathrm{mM}$ and $25 \mathrm{mM}$ as final concentration. The proportion of methanol:PMMA is $1: 2$ in $400 \mathrm{mM}$ and $1: 3$ in all other concentrations. Then R6G was spin coated on the Ag particles which were prepared by hole-mask colloidal lithography with 3000 rpm for 1 min. R6G was also spin coated on cover glass slides as control group. The photograph of the samples and control glass slides are given in Figure S14 (a). The photograph also shows a silver nanodisk substrate without R6G on the bottom row. The transmission of the samples and the controls are shown in Figure S14 (c) and (d) respectively. The scattering of the same samples and control are given in Figure S14 (e) and (f) with the same color code and legends. Figure S14 (f) shows that the scattering is completely suppressed around 470-580 nm wavelength range due to dominating absorption.

Figure S14 (b) shows the Ag nanodisks covered by $25 \mathrm{mM}$ ordinary R6G in methanol:PMMA in two different ways to compare the contribution of R6G-Ag interaction. First, R6G was directly spin coated on Ag nanodisks (light blue curve). Secondly, Ag nanodisks were only spin coated with PMMA without any dye (dark blue curve) and R6G in PMMA was spin coated on cover glass (pink curve). These Ag and R6G substrates were put on top each other and measured together (orange curve). In this way, it was aimed if the contribution from R6G and Ag particles can be separated in the spectra. The light blue and orange curves show similar spectra except the fact that the plasmon peak of the particles is more red-shifted when R6G was directly spin coated on the particles. 
a
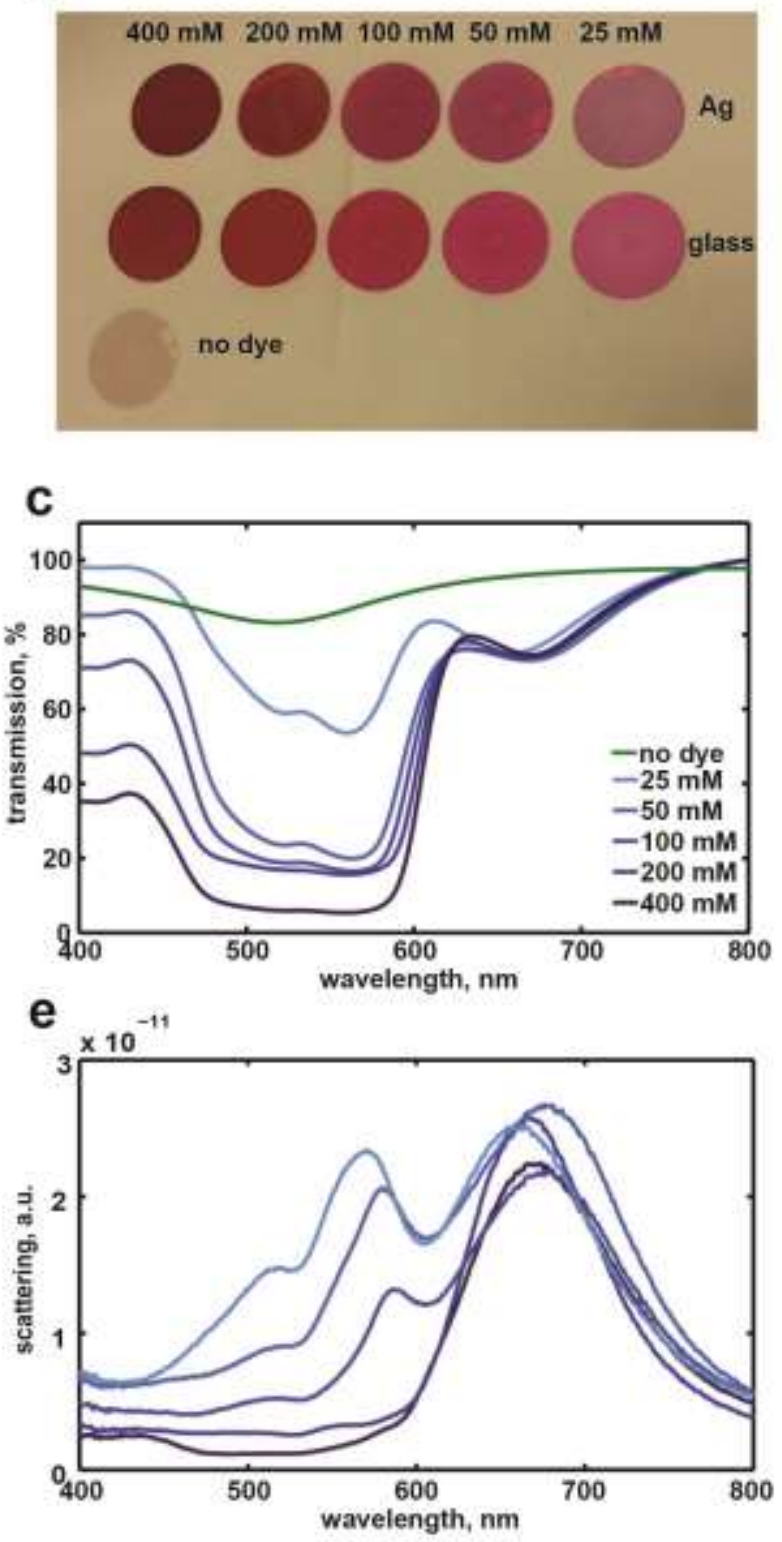

b

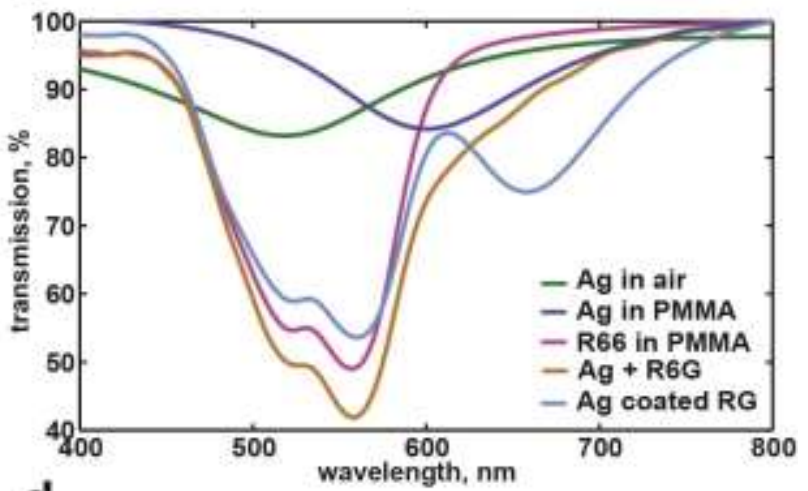

d

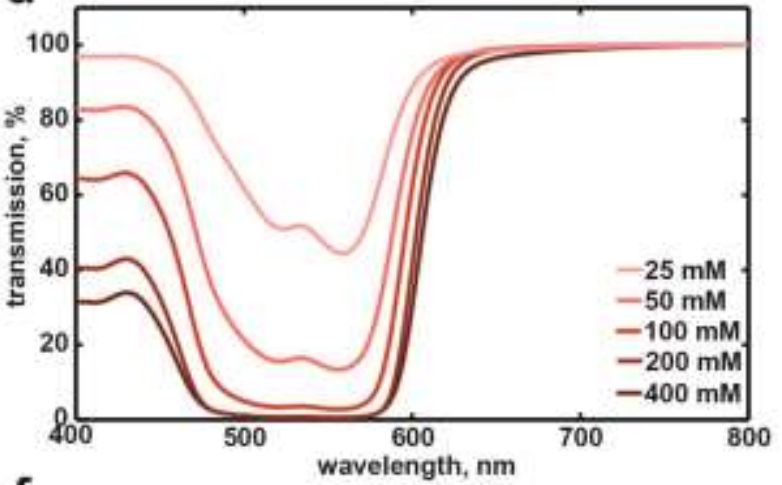

$f$

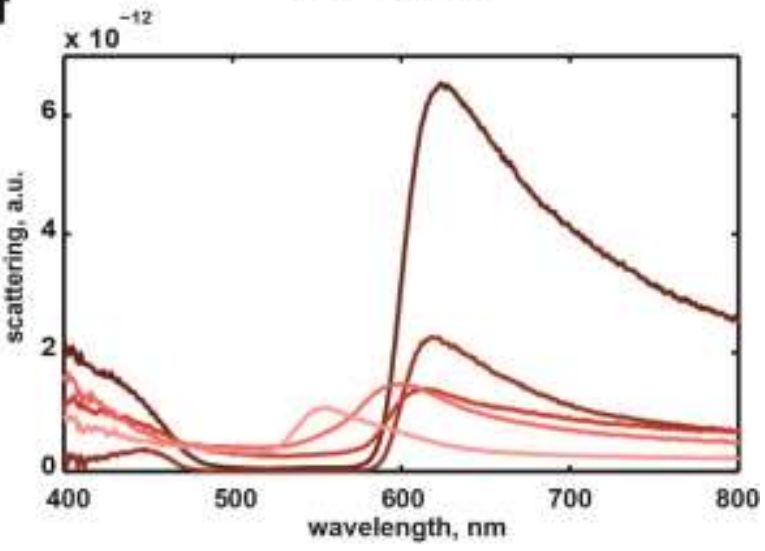

Figure S14 - (a) Photographs of ordinary R6G spin coated on Ag nanodisks and cover glass with $25 \mathrm{mM}, 50 \mathrm{mM}$, $100 \mathrm{mM}, 200 \mathrm{mM}$ and $400 \mathrm{mM}$ concentrations. (b) Transmission spectra of Ag nanodisks in air (green), in PMMA (dark blue), R6G in PMMA (pink), Ag nanodisks spin coated with R6G in PMMA (light blue), and Ag nanodisks in PMMA placed on top of R6G in PMMA (orange). The concentration of R6G is $25 \mathrm{mM}$. (c) Transmission spectra of Ag nanodisks spin coated with different R6G concentrations in PMMA 25 mM, 50 mM, 100 mM, 200 mM, and $400 \mathrm{mM}$. (d) Transmission spectra of cover glass slides spin coated with different R6G concentrations in PMMA $25 \mathrm{mM}, 50 \mathrm{mM}, 100 \mathrm{mM}, 200 \mathrm{mM}$, and $400 \mathrm{mM}$. (e) Scattering spectra of Ag nanodisks spin coated with different R6G concentrations in PMMA 25 mM, 50 mM, $100 \mathrm{mM}, 200 \mathrm{mM}$, and $400 \mathrm{mM}$. (f) Scattering spectra of cover glass slides spin coated with different R6G concentrations in PMMA 25 mM, 50 mM, 100 mM, 200 mM, and $400 \mathrm{mM}$. 


\section{Surface characterization of ordinary R6G in high concentrations}

The micrograph of the same samples and controls are given in Figure S15 (a) and (b). The first columns show micrographs under transmission and the second columns show micrographs under scattering modes. Ordinary R6G forms grainy structure when solved in PMMA and spin coated on surface. When the concentration of ordinary R6G increases, R6G grains become bigger. Figure S15 (c) shows scanning electron microscopy images of controls at the crosssection. Even though only PMMA A2 spin coating results in around $50 \mathrm{~nm}$ thickness, when R6G is solved in PMMA it resulted in thicker layers. The layer thickness increases further with the increased dye concentration. Even in the most diluted case, $25 \mathrm{mM}$, it is still too thick for interaction of plasmonic nanostructures.
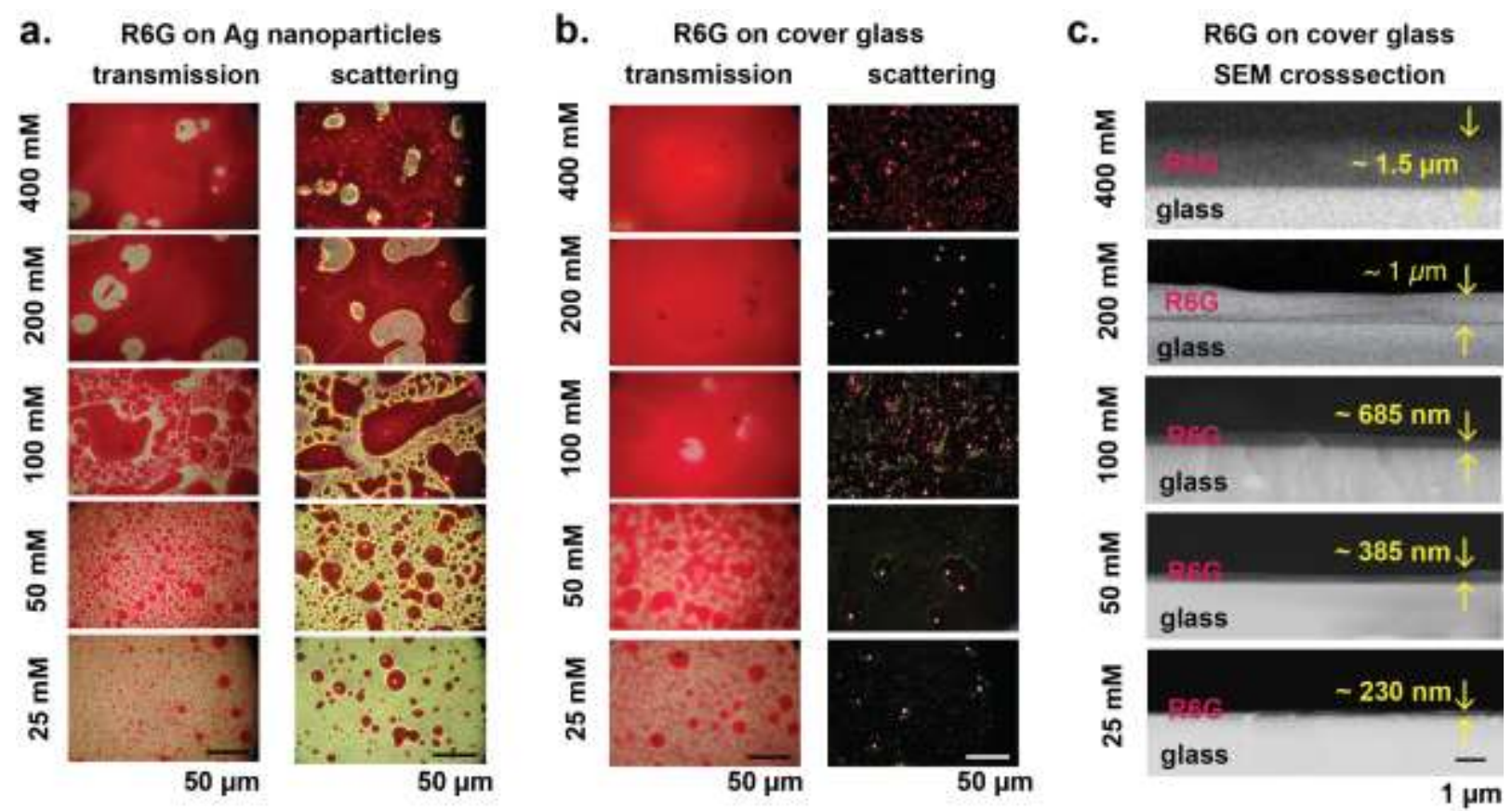

Figure S15 - The micrograph of the samples and controls are given in (a) and (b) with 25-400 mM ordinary R6G concentration. The first columns show the images taken under transmission and the second columns show the images taken under scattering modes. (c) The scanning electron micrograph of controls at the crosssection and thickness of the ordinary R6G layers on glass for the same concentrations. 


\section{Estimation of transitional dipole moment of R6G}

Transitional dipole moment of R6G for $531 \mathrm{~nm}$ peak is estimated to be $1.74 \mathrm{D}$ from absorption cross section as following:

$\mu_{R 6 G}=\left(\frac{3}{4 \pi^{2}} \hbar \sigma_{R 6 G} \gamma_{0} \varepsilon_{0} \lambda\right)^{0.5}$

$\sigma_{R 6 G}$ is absorption cross-section of R6G at peak maximum: $3 \times 10^{-16} \mathrm{~cm}^{2}$.

$\gamma_{0}$ is the full width half maximum of absorption spectrum of R6G in $s^{-1}$. This value is taken as $974 \mathrm{~cm}^{-1}$ in ethanol for the main peak. ${ }^{[8]}$

$\varepsilon_{0}$ is the vacuum permittivity.

$\lambda$ is the resonance wavelength and taken as $531 \mathrm{~nm}$.

\section{References:}

[1] X. Chen, S.-W. Nam, M. J. Jou, Y. Kim, S.-J. Kim, S. Park, J. Yoon, Org. Lett. 2008, $10,5235-8$.

[2] Y. Yang, H. J. Cho, J. Lee, I. Shin, J. Tae, 2009, 5-7.

[3] H. Sasaki, K. Hanaoka, Y. Urano, T. Terai, T. Nagano, Bioorg. Med. Chem. 2011, 19, 1072-8.

[4] M. Adamczyk, J. Grote, Bioorg. Med. Chem. Lett. 2003, 13, 2327-2330.

[5] P. Thebault, E. Taffin de Givenchy, R. Levy, Y. Vandenberghe, F. Guittard, S. Géribaldi, Eur. J. Med. Chem. 2009, 44, 717-24.

[6] A. I. Väkeväinen, R. J. Moerland, H. T. Rekola, A.-P. Eskelinen, J.-P. Martikainen, D.H. Kim, P. Törmä, Nano Lett. 2014, 14, 1721-7.

[7] S. R. K. Rodriguez, J. G. Rivas, Opt. Express 2013, 21, 27411.

[8] J. A. Dieringer, K. L. Wustholz, D. J. Masiello, J. P. Camden, S. L. Kleinman, G. C. Schatz, R. P. van Duyne, J. Am. Chem. Soc. 2009, 131, 849-854. 